tal cancer patients with liver metastases. $\mathcal{F}$ Surg Oncol 1987, 34, 81-86.

12. Edler L, Heim ME, Quintero C, Brummer T, Queisser W. Prognostic factors of advanced colorectal cancer patients. Eur $\mathcal{J}$ Cancer Clin Oncol 1986, 22, 1231-1237.

13. Steinberg J, Erlichman C, Gadalla T, Fine S, Wong T. Prognostic factors in patients with metastatic colorectal cancer receiving 5 fluorouracil and folinic acid. Eur $\mathcal{F}$ Cancer 1992, 28A, 1817-1820.

14. Graf W, Glimelius B, Påhlman L, Berström. Determinants of prognosis in advanced colorectal cancer. Eur $\mathcal{F}$ Cancer 1991, 27, $1119-1123$.

15. Nordic Gastrointestinal Tumor Adjuvant Therapy Group. Biochemical modulation of 5-fluorouracil: a randomized comparison of sequential methotrexate, 5 -fluorouracil, and leucovorin versus sequential 5-fluorouracil and leucovorin in patients with advanced colorectal cancer. Ann Oncol 1993, 4, 235-240.

16. Cox DR. Regression models and life-tables. I $R$ Stat Soc 1972, 34, 187-220.

17. Fortner JG, Silva JS, Cox EB, Golbey RB, Gallowitz H, Maclean B. Multivariate analysis of a personal series of 247 patients with liver metastases from colorectal cancer. II Treatment by intrahepatic chemotherapy. Ann Surg 1984, 199, 317-324.

18. Tartter PI. Pretreatment prognostic factors in colorectal cancer patients with synchronous liver metastases. Eur f Surg Oncol 1987 , 13, 485-491.

\title{
The Costs of Peripheral Blood Progenitor Cell Reinfusion Mobilised by Granulocyte Colony- stimulating Factor Following High Dose Melphalan as Compared with Conventional Therapy in Multiple Myeloma
}

\author{
C.A. Uyl-de Groot, G.J. Ossenkoppele, A.A.P.M. van Riet and F.F.H. Rutten
}

In a retrospective study, we calculated the treatment costs of 26 patients, who received either high dose melphalan combined with granulocyte colony-stimulating factor (G-CSF; filgrastim) $(n=7)$ or without G.CSF $(n=11)$ or alternatively, peripheral blood progenitor cell reinfusion (PBPC) mobilised by G-CSF following high dose melphalan. In comparison with the control group, a shortening of the pancytopenic period and platelet recovery was noticed in the PBPC group. This resulted in a reduction in hospital costs, diagnostics, laboratory services, total parenteral nutrition and transfusions. The average costs per treatment in the PBPC group amounted to about US $\$ 17908$ as compared to US\$ 32223 in the control group, implying a cost reduction of $44 \%$ when changing to PBPC reinfusion.

Key words: costs, cancer, multiple myeloma, peripheral blood stem cells, G-CSF

Eurf Cancer, Vol. 30A, No. 4, pp. 457-459, 1994

\section{INTRODUCTION}

HIGH DOSE melphalan is associated with high response rates in multiple myeloma, but the treatment associated morbidity and mortality is high (about $20 \%$, due to complications of prolonged granulocytopenia) [1,2]. Transplantations with stem cells

Correspondence to C.A. Uyl-de Groot.

C.A. Uyl-de Groot, A.A.P.M. van Riet and F.F.H. Rutten are at the Institute for Medical Technology Assessment/Department of Health Care Policy and Management, Erasmus University Rutterdam, P.O. Box 1738, 3000 DR Rotterdam; and G.J. Ossenkoppele is at the Department of Haematology, Free University Hospital, De Boelelaan 1117,1081 HV Amsterdam, The Netherlands.

Revised 22 Nov. 1993; accepted 21 Jan. 1994. derived cither from bone marrow or from peripheral blood, and or the administration of colony-stimulating factors are performed to hasten granulocyte recovery $[3,4]$. Peripheral blood progenitor cell (PBPC) transplantation is increasingly used in the treatment of malignancies to alleviate bone marrow toxicity resulting from high dose chemotherapy. It is introduced as an alternative to autologous bone marrow transplantation (ABMT) and has several advantages over ABMT, such as avoiding anaesthesia. It seems that infusion of PBPC after high dose chemotherapy is associated with markedly accelerated platelets and neutrophil recovery as compared to ABMT [4-6].

This study focuses on the costs associated with the treatment of multiple myeloma patients. The results are based on a 
retrospective study of detailed records of 26 patients. The treatment modalities were high dose melphalan combined with or without the granulocyte colony-stimulating factor (G-CSF; filgrastim), or G-CSF mobilised by PBPC transplantation following high dose melphalan.

\section{PATIENTS AND METHODS}

The study included 26 patients with multiple myeloma. The PBPC group consisted of 8 patients. PBPC were mobilised by G-CSF subcutaneously, and subsequently 11 of whole blood was collected by phlebotomy, kept unprocessed at room temperature and reinfused $24 \mathrm{~h}$ after high dose melphalan [7]. These patients were compared with a group of 18 patients with multiple myeloma who met the same criteria and whose pretreatment characteristics were equivalent. This group consisted of 11 patients who received no G-CSF, 4 patients who received GCSF starting at day 28, and 3 patients starting at day 3 after chemotherapy. Despite the addition of G-CSF to 7 patients, there was no difference with regard to neutrophil and platelet recovery, days with fever, number of transfusions or hospital stay between these 7 patients and the other 11 patients in the control group.

The costs that were studied concerned days in hospital, laboratory services, diagnostics (mainly $\mathrm{X}$-rays), the insertion of a subclavian catheter, medication (antibiotics, etc.) and blood transfusions. Data on these costs were collected through cost registry forms.

Statistical methods included Wilcoxon tests for comparisons of costs and for comparisons of time-to-event outcomes for the days in hospital [8].

\section{Unit prices}

For each of the activities mentioned above, unit prices were determined reflecting the real use of resources. The costs of hospital days were divided into direct and indirect costs. The direct costs concerned manpower (doctors, nurses, etc.) and materials (medical services, supportive patient care, etc.). The indirect costs related to overheads. The costs of hospitalisation amounted to approximately US\$ 350 per day for normal haematological care, and US\$1165 for intensive care. None of the patients were treated in a protected environment.

The output of laboratories in the Netherlands is measured in terms of a point system, and by each point (unit of output) a cost per unit or price may be associated, which differs across types of laboratories. The prices per point varied from US\$0.62 (biochemistry and haematology laboratories) to US $\$ 2.81$ (virology tests), the price of a routine test, (including haemoglobin, haematocrit, leucocyte and thrombocyte levels) amounted to 5.75 points and cost US\$ 3.58.

For all other diagnostics, the Dutch tariff system has been used as an approximation of unit costs (a chest X-ray approximately US $\$ 31.00$ and an electrocardiogram US\$22.00). The costs of the insertion of a subclavian catheter were US $\$ 04.00$ (including the costs of a catheter). The drug prices used were wholesale prices. The costs of $300 \mathrm{mg}$ melphalan (intravenous) amounted to US $\$ 289.00$ and the costs of a $300 \mu \mathrm{g}$ vial of G-CSF (intravenous) to US\$138.00. (See Appendix for a list of unit prices used in this study.)

\section{Clinical results}

\section{RESULTS}

For the 8 patients treated with high dose melphalan and reinfusion of PBPC, the median time to recovery of granulocytes
Table 1. Clinical results

\begin{tabular}{lcc}
\hline Clinical data & $\begin{array}{c}\text { PBPC group } \\
\text { Melphalan }+ \\
\text { G-CSF }+ \text { PBPC }\end{array}$ & $\begin{array}{c}\text { Control group } \\
\text { Melphalan } \pm \\
\text { G-CSF }\end{array}$ \\
\hline Days granulocytes $>0.5 \times 10^{9} / 1$ & $12.5(10-35)^{*}$ & $38.0(24-65)$ \\
Days granulocytes $>1.0 \times 10^{9} / 1$ & $14(12-55)^{*}$ & $42(26-72)$ \\
Days platelets $>20 \times 10^{9} / 1$ & $23.5(14-115)^{\dagger}$ & $36.0(25-172)$ \\
Hospital stay in days & $19(16-39)^{*}$ & $43(33-71)$ \\
Days of antibiotic use & $8(0-37)^{*}$ & $21(0-48)$ \\
Number of platelet transfusions & $21(12-102)^{*}$ & $54(30-228)$ \\
Number of red cell transfusions & $6(3-21)^{*}$ & $12(3-66)$ \\
\hline
\end{tabular}

Values are expressed as median (range). ${ }^{*} P$ value $<0.01$. ${ }^{+} P$ value $<0.05$.

to $0.5 \times 10^{9}$ was 12.5 days, for recovery of granulocytes to 1.0 $\times 10^{9} / 1$ was 14 days, and for platelet recovery to $20 \times 10^{9} / 1$ was 23.5 days (Table 1). In comparison with the control group, the pancytopenic period and period to platelet recovery were significantly shortened. There was 1 patient whose results differed from the control group. This patient had received half body irradiation as second line therapy. G-CSF was well tolerated and no adverse effects were observed. Only 1 patient developed fever after reinfusion.

The patients in the PBPC group had a median hospital stay of 19 days as compared with 43 days in the control group $(P<0.0001)$ (Figurel). Only 1 patient was treated in the intensive care department. This patient belonged to the control group and stayed there for 6 days.

The number of days of antibiotic use decreased from 21 to 8 days. Furthermore, the number of platelet transfusions was reduced significantly from 54 to 21 transfusions. The number of red cell transfusions also decreased, but the reduction was not significant.

\section{Cost analysis}

Table 2 presents the average treatment costs per category of costs. The costs of hospitalisation decreased by more than $50 \%$, from US $\$ 16747$ to US $\$ 7335(P<0.005)$. The costs of laboratory services, antibiotics and other medication, nutrition and transfusions were also significantly lower in the PBPC group.

The costs of G-CSF were relatively low in the control group, because not all patients received G-CSF. The costs of antibiotics and other medications reduced markedly, from US\$ 6476 to

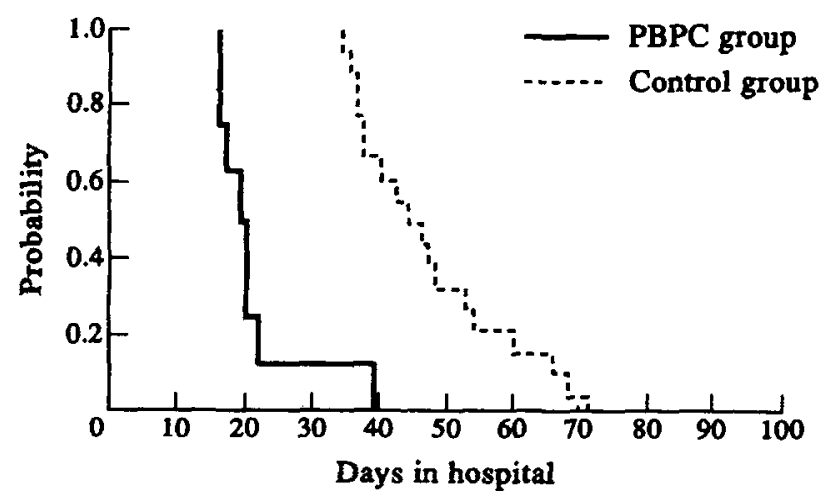

Figure 1. Days in hospital. 
Table 2. The average treatment costs of multiple myeloma patients (US\$) $(1$ dollar $\approx 1.8$ Dutch guilders $)$

\begin{tabular}{lcc}
\hline & $\begin{array}{c}\text { PBPC group } \\
\text { Melphalan }+ \\
\text { G-CSF + PBPC }\end{array}$ & $\begin{array}{c}\text { Control group } \\
\text { Melphalan } \\
\text { G-CSF }\end{array}$ \\
\hline Hospitalisation (hotel) & $7335^{*}$ & 16747 \\
Laboratory services & $767^{*}$ & 1776 \\
Diagnostics & $765^{*}$ & 921 \\
G-CSF (filgrastim) & $5293^{*}$ & $1393^{*}$ \\
Antibiotics and other medication & $2454^{*}$ & 6476 \\
Nutrition & $229^{*}$ & 2148 \\
Transfusions & $1065^{\dagger}$ & 2762 \\
Total treatment costs & $17908^{*}$ & 32223 \\
\hline
\end{tabular}

${ }^{*} P$ value $<0.01 .{ }^{+} P$ value $<0.05$

US $\$ 2454(P<0.01)$. When the costs of G-CSF were combined with all other medications, the costs in the study group were somewhat lower (US\$7747 versus US\$ 7869), but this difference was not significant. Only 3 patients in the PBPC group received total parenteral nutrition, while in the control group all patients received parenteral nutrition. The costs of nutrition decreased from US\$2148 to US\$229 $(P<0.001)$. The costs of blood transfusions were reduced by more than $60 \%$, from US\$2762 to US\$1065 $(P<0.05)$. The total treatment costs decreased by $44 \%(P<0.005)$. The hospitalisation costs in the PBPC group were responsible for $41 \%$ of the total costs, and for almost $52 \%$ in the control group.

\section{DISCUSSION}

The clinical results of PBPC reinfusion mobilised by G-CSF collected by simple phlebotomy without further processing showed a remarkable shortening of the haematopoietic recovery period in patients with multiple myeloma treated with high dose melphalan. The neutropenic recovery was shortened with a median of 25.5 days, and the platelet recovery was also accelerated. This resulted in a remarkable decrease in hospital days and reduced use of antibiotics, platelet and red cell transfusions. One may argue that the addition of G-CSF to all patients in the control group would result in a cost reduction. However, the addition of G-CSF did not result in a reduction in the number of transfusions or in the length of hospital stay in the patient group studied. Therefore, we do not expect a decrease in the total costs in the control group when G-CSF is provided to all patients.

In general, when new treatment modalities become available, the additional financial burden that these treatments place on the health care system raises concern. However, in this study, PBPC reinfusion mobilised by G-CSF accounted for a remarkable reduction in costs. The reduction was observed regarding all activities in the treatment process. An improvement in the quality of life during the remission period has not been documented, but may also be expected.

PBPC reinfusion appears to be a promising approach with a favourable cost-effectiveness profile, but further research is needed to show the real benefits from the patient perspective.

1. Lokhorst HM, Meuwissen OJATh, Verdonck LF, Dekker AW. High-risk multiple myeloma treated with high-dose melphalan. $f$ Clin Oncol, 1992, 10, 47-51
2. Selby PJ, McElwain TJ, Nandi AC, et al. Multiple myeloma treated with high dose intravenous melphalan. $\mathrm{Br} 7 \mathrm{Haematol}$ 1987, 66. $55-62$.

3. Barlogie B, Jagannath S, Dixon D, et al. High dose melphalan and granulocye-macrophage colony-stimulating factor for refractory multiple myeloma. Blood 1990, 76, 677-680.

4. Kessinger A, Armitage JO, Smith DM, Landmark JD, Bierman PJ Weisenburger DD. High-dose therapy and autologous peripheral blood stem cell transplantation for patients with lymphoma. Blood $1989,74,1260-1265$

5. Advani R, Chao NJ, Horning SJ, et al. Granulocyte macrophage colony-stimulating factor (GM-CSF) as an adjunct to autologous hemopoietic stem cell transplantation for lymphoma. Ann Intern Med 1992, 116, 183-189.

6. Siena S, Bregni M, Brando B, Ravagnani F, Bonadonna G, Gianni $\mathrm{AM}$. Circulation of $\mathrm{CD} 34^{+}$hematopoietic stem cells in the peripheral blood of high-dose cyclophosphamide-treated patients; enhancement by intravenous recombinant human granulocyte-macrophage colony-stimulating factor. Blood 1989, 74, 1905-1914.

7. Ossenkoppele GJ, Jonkhoff AR, Huijgens PC, et al. Peripheral blood progenitors mobilised by G-CSF (filgrastim) and reinfused as unprocessed autologous whole blood shorten the pancytopenic period following high dose melphalan in multiple myeloma. Bone Marrow Transplantation 1994, 13, 37-41.

8. Glantz SA. Primer of Biostatistics. Singapore, McGraw-Hill Book Inc., 1989, 287-330.

Acknowledgement-Amgen and Roche are gratefully acknowledged for their support during this study.

\section{APPENDIX}

$\begin{array}{ll} & \text { Unit prices }\end{array}$

Hospital stay

Normal haematological care $\quad 350.00$

Intensive care $\quad 1165.00$

Laboratories

Haematology ( $\mathrm{Hb}, \mathrm{Ht}$, leucocytes,

thromobocytes

3.58

Biochemistry $(\mathrm{Na}, \mathrm{K}$, creatinine, glucose $) \quad 10.58$

Urine 1 ( $\mathrm{pH}$, glucose, albumin, urobilin,

bilirubin, sediment)

Urine 2 (creatinine, $\mathrm{Na}$, albumin, total protein) 8.71

Cultures (blood, urine, sputum) 20.50

Virology tests

72.94

Cytology (bone marrow, bronchus)

Diagnostics

$\mathrm{X}$-ray chest

30.94

$\mathrm{X}$-ray sinus

36.92

Electrocardiogram (ECG)

22.00

Bronchoscopy

430.33

Computed tomography scan

219.44

Echo

74.78

Insertion subclavian catheter $\quad 504.00$

Total parenteral nutrition $\quad 83.33$

Platelet transfusions

Red cell transfusions $\quad 98.89$

Drugs

Melphalan (300 mg iv) $\quad 289.00$

G-CSF (Neupogen) $(300 \mu$ g iv) $\quad 138.00$

Antibiotics and other medication:
e.g. Ciprofloxacin $1000 \mathrm{mg}$ iv

Fluconazole $50 \mathrm{mg}$ oral $\quad 5.18$

Tienam $500 \mathrm{mg}$ iv $\quad 23.61$

Vancomycin $1000 \mathrm{mg}$ iv $\quad 66.14$

Zovirax $250 \mathrm{mg}$ iv $\quad 24.98$

Zofran $8 \mathrm{mg}$ iv $\quad 34.95$

$\mathrm{Hb}$, haemaglobin; $\mathrm{Ht}$, haematocrit; iv, intravenous 